\title{
Aromaticity in Heterocyclic Analogues of Benzene: Comprehensive Analysis of Structural Aspects, Electron Delocalization and Magnetic Characteristics.
}

\author{
Irina V. Omelchenko ${ }^{a}$, Oleg V. Shishkin ${ }^{\mathrm{a}, \mathrm{b}, *}$, Leonid Gorb ${ }^{\mathrm{c}, \mathrm{d}}$, Jerzy Leszczynski ${ }^{\mathrm{c}}$, \\ Stijn Fias ${ }^{\mathrm{e}}$ and Patrick Bultinck ${ }^{\mathrm{e}, *}$
}

${ }^{a}$ SSI 'Institute for Single Crystals' National Academy of Sciences of Ukraine, 60 Lenina ave., Kharkiv 61001,Ukraineshishkin@xray.isc.kharkov.com

${ }^{b}$ Department of Inorganic Chemistry, V. N. Karazin Kharkiv National University, 4 Svobody sq., Kharkiv 61077, Ukraine

${ }^{c}$ Interdisciplinary Center for Nanotoxicity, Department of Chemistry Jackson State University, P.O. Box 17910, 1325 Lynch Street, Jackson, MS 39217, USA

${ }^{d}$ Department of Molecular Biophysics, Institute of Molecular Biology and Genetics, National Academy of Sciences of Ukraine, 150 Vul. Zabolotnogo, Kyiv 03143, Ukraine

${ }^{e}$ Department of Inorganic and Physical Chemistry, Ghent University, Krijgslaan 281 (S3), B9000 Gent, Belgium.Patrick.Bultinck@UGent.be 


\begin{abstract}
The degree of aromaticity of six-membered monoheterocycles with IV - VI group heteroatoms $\left(\mathrm{C}_{6} \mathrm{H}_{5} \mathrm{X}\right.$, where $\left.\mathrm{X}=\mathrm{SiH}, \mathrm{GeH}, \mathrm{N}, \mathrm{P}, \mathrm{As}, \mathrm{O}^{+}, \mathrm{S}^{+}, \mathrm{Se}^{+}\right)$was analyzed using the results of ab initio calculations at the MP2/cc-pvtz level. Values of common aromaticity indices including those based on electronic delocalization properties, structural-dynamic features and magnetic properties all indicate high aromaticity of all considered heterocycles. A decrease in aromaticity is observed with increasing atomic number of the heteroatom, except in the case of the pyrylium cation. However, not all types of indices or even different indices within the same type correlate well among each other. Ring currents have been obtained at the HF/cc-pvdz level using the ipsocentric formulation. Ring current maps indicate that in the case of cationic heterocycles the ring current persists in all molecules under consideration. The different conclusions reached depending on the type of index used, are a manifestation of the fact that when not dealing with hydrocarbons, aromaticity is illdefined. One should always express explicitly which property of the molecules is considered to establish a degree of "aromaticity".
\end{abstract}

Keywords: aromaticity; aromaticity index; conformational flexibility; six-membered heterocycles, ring current.

\title{
INTRODUCTION
}

Aromaticity is one of the fundamental concepts in organic chemistry. ${ }^{1}$ Qualitative definitions of aromaticity were formulated long $\mathrm{ago}^{2}$ on the basis of the structure of benzenoid hydrocarbons and their "unusual" properties namely their symmetric structure with bond length equalization, thermodynamic stability, reactivity, special magnetic properties etc. These compounds composed of only carbon atoms do not exhibit significant intrinsic 
polarization of the $\sigma$-skeleton, creating very favorable conditions for $\pi$-electron delocalization.

Assessing the degree of aromaticity of cyclic conjugated systems requires some quantitative descriptors. Many indices of aromaticity have been suggested for this purpose. All earlier indices are based on experimental data only (e.g., reactivity in the Diels-Alder reaction, burning or hydrogenation). ${ }^{1}$ However, their values depend significantly on the experimental conditions, methods of experimental measurement, available reagents, etc. Therefore, comparison of the values obtained can be a very difficult task. Computational chemistry methods allow overcoming the limitations of having to use experimental data. Most traditional aromaticity indices are based on some common physico-chemical properties of aromatic molecules, ${ }^{3}$ and can be divided into several groups. Minkin et al. ${ }^{1}$ distinguish i) structural indices (Bird ${ }^{4,5,6}$ and Pozharskii ${ }^{7}$ indices and HOMA $^{8,9,10}$ (Harmonic Oscillator Model of Aromaticity)) reflecting endocyclic bond order or bond length equalization; ii) magnetic indices (from anisotropy and exaltation of magnetic susceptibility ${ }^{11,12}$ to Nuclear Indepedenent Chemical Shift or NICS ${ }^{13,14}$ ) concerned with the particular magnetic properties of the aromatic ring, and iii) energetic indices including different resonance energies ${ }^{3}$. Later, electron delocalization indices such as the para-delocalization index (PDI), ${ }^{15,16}$ fluctuation index (FLU), ${ }^{15,17}$ and multi-center bond index (MCBI) ${ }^{18,19}$ were introduced. Numerous indices based on Bader's Quantum Theory of Atoms in Molecules (QTAIM) ${ }^{20,21}$ have also been used as electronic criteria. As an example, it was shown that the value of the electron density in the ring critical point $(\mathrm{RCP})$ can be used as quantitative characteristic of $\pi$-electron delocalization. ${ }^{22,23,24,25}$

However, many of the aromaticity indices mentioned above have some unavoidable limitations. ${ }^{3}$ For example, the Bird and Pozharskii structural indices are commonly used with the Gordy equation that needs empirically standardized coefficients ${ }^{4,7}$ as otherwise there is 
ambiguity in the bond order evaluation. Moreover, they do not allow estimating correctly the aromaticity of highly symmetric molecules such as symm-triazine or hexafluorobenzene. ${ }^{26}$ The HOMA index also includes empirical coefficients, and sometimes overestimates the aromaticity of nitrogen-containing compounds. ${ }^{3}$ NICS is sensitive to $\sigma$-electronic effects and depends on the ring size and the level of theory applied. ${ }^{14}$ Evaluation of the most popular energetic index, Aromatic Stabilization Energy (ASE), ${ }^{3}$ requires different schemes for different types of molecules, hampering their comparison. In general, there is no universal index that is equally good for all types of compounds, and it has been suggested that one should consider many of them to reach a conclusion.

The meaning of correlations or even more the lack of correlation between aromaticity indices remains one of the most controversial issues in modern theoretical organic chemistry. ${ }^{1}$ Intuitively, one expects that they should correlate well. Analysis of a number of fivemembered heterocycles carried out using NICS, ASE and other popular indices indicates ${ }^{27}$ divergence or lack of correlation between various kinds of indices. Although it was known earlier that good agreement can be observed for some pairs of indices for selected types of molecule, ${ }^{28}$ it was concluded that the divergence described above reflects a multi-dimensional nature of aromaticity. ${ }^{29,30}$ Therefore, it is often stated that correct analysis of aromaticity must include several indices of different types. On the other hand, in some cases there is a strikingly good correlation between different indices. This is the case, for example, homoaromatic compounds where NICS agrees well with conclusions from MCBI. ${ }^{31}$ Also in other cases, such as that of polycyclic aromatic hydrocarbons, no multidimensional character is needed to explain the lack of correlation between NICS and MCBI. In this case, the lack of correlation can be simply related to the fact that MCBI and NICS inherently reflect other phenomena that can, however, still be reconciled..$^{32,33,34}$ True multidimensional character on 
the other hand has been found recently when considering domain averaged Fermi holes, $\mathrm{MCBI}$ and ring currents in the case of all metallic aromatic systems such as $\mathrm{Al}_{4}$ rings. ${ }^{35}$

So-called structural-dynamic indices have a clear connection with experimental data. Although it is often assumed that aromaticity depends critically on the planarity of the molecule involved, it has been shown that resonance energies do not change dramatically upon deviation from planarity. ${ }^{36}$ This agrees with the findings of some of us who confirmed that aromatic rings possess a significant degree of conformational flexibility. ${ }^{37}$ It was shown that some deviations of the ring from planarity (with values of endocyclic torsion angles up to $30^{\circ}$ ) do not prohibit cyclic $\pi$-electron delocalization. Aromatic ring flexibility seems to be directly related to the strength of $\pi$-bonding and the degree of aromaticity. It is sensitive to the type of aromatic ring and to the substituents as was revealed by investigation of the out-ofplane deformations of polycyclic hydrocarbons ${ }^{38}$, azaanalogues of naphthalene, ${ }^{39}$ adenine and related molecules ${ }^{40}$. The energy needed for out-of-plane deformation correlates well with the degree of aromaticity as was shown in particular for monosubstituted benzenes. ${ }^{41}$ Therefore, it can also be used as a quantitative index.

Replacement of one or several $\mathrm{CH}$ groups of the benzene ring by a heteroatom results in considerable changes in the intramolecular interactions within the benzene ring. The different electronegativity and size of heteroatoms causes polarization of the $\sigma$-skeleton and the $\pi$ system, changes in the carbon-heteroatom bond lengths and the degree of overlap between $\mathrm{p}_{\mathrm{z}^{-}}$ atomic orbitals. Therefore one could also anticipate considerable changes in aromaticity in heterocyclic analogues of benzene. ${ }^{1}$ A common observation is the decrease in aromaticity upon increasing atomic number of the heteroatom and increase in the number of heteroatoms within the ring. However, calculations of aromaticity indices indicate that these simple rules fail in some cases. For example, the degree of aromaticity in some nitrogen-containing rings ${ }^{42}$ and a wide range of five-membered species ${ }^{43}$ is almost the same as benzene or even higher. 
Extended studies of pyridine and other azines demonstrated that these molecules keep a high degree of $\pi$-electronic delocalization within the ring and remain highly aromatic ${ }^{1,44}$ although less aromatic than benzene. This infers that the presence of the nitrogen atom only slightly perturbs the aromatic system of benzene. Considerably stronger perturbations are supposed in the case of the pyrylium cation. ${ }^{3,45}$ The presence of heavier heteroatoms leads to different consequences. Phosphorus, arsenic and antimony analogues of pyridine exhibit lower aromaticity than benzene ${ }^{3}$ and pyridine ${ }^{46,47}$. However, according to values of the resonance energy $^{48}$ and the delocalization enthalpy ${ }^{49}$ they remain clearly aromatic. Moreover, comparative theoretical studies of the structure and properties of pnictogen heterobenzenes $\mathrm{C}_{5} \mathrm{H}_{5} \mathrm{X}$ (where $\mathrm{X}=\mathrm{N}, \mathrm{P}, \mathrm{As}, \mathrm{Sb}, \mathrm{Bi}$ ) led to the conclusion that phosphabenzene is more aromatic than pyridine. ${ }^{50}$ However, this does not agree with the reactivity of this compound. ${ }^{51}$ Moreover, the NICS values for all these compounds are very similar.

A different trend is observed for the analogues of the pyrylium cation. The thiopyrylium cation seems to be more aromatic than pyrylium. ${ }^{3,15}$ Further increase of the size of the heteroatom results in a decrease in aromaticity of the $\pi$-system in seleno- and telluropyrylium cations $^{3}$. A detailed investigation of the pyrylium cation by different methods led to the conclusion that it is aromatic. However, only a low contribution of localized resonance structures with three double bonds within the ring was found. ${ }^{52}$

Contrary to other heterocycles, sila- and germabenzenes are rather unstable. ${ }^{53,54}$ This causes significant problems for their experimental investigation. However, spectral data and structural analysis ${ }^{55,56}$ suggest significant aromatic character of the cyclic conjugated system in these compounds in agreement with early theoretical studies. ${ }^{57}$ Later calculations of NICS, HOMA and ASE indices demonstrated ${ }^{58,59}$ that sila- and germabenzenes are highly aromatic. The same conclusion was reached based on an Electron Localization Function (ELF) study. ${ }^{60}$ However, higher reactivity of the $\mathrm{C}-\mathrm{Si}$ and $\mathrm{C}-\mathrm{Ge}$ bonds with respect to addition reactions 
compared to the C-C bonds in benzene was found. ${ }^{54,56}$ This suggests considerably lower aromaticity of sila- and germabenzene compared to benzene. ${ }^{61}$

Despite the great interest in the aromaticity of monoheterocycles only a few attempts of their systematic study were published. Priyakumar and Sastry investigated skeletally substituted benzenes ${ }^{62}$ using accurate calculations for mono- and diheterocycles with heteroatoms of the III-V groups with emphasis on the distortion tendencies of aromatic rings although without numerical examination of aromaticity using the indices mentioned above. A recent paper by Kassaee et al. ${ }^{63}$ dealt with monoheterocycles with IV - VI group heteroatoms and applied popular aromaticity indices for them. Ebrahimi et al ${ }^{64}$ focused on the topological properties of the electron density such as the ring critical point and their correlation with NICS and isodesmic resonance energy of the six-membered monoheterocycles. However, these calculations were performed at the B3LYP level of theory that seems to be insufficiently accurate especially for energetic indices. ${ }^{3,65}$ Besides these studies, there is no systematic comparison of different indices.

As the above survey of literature shows, there appears to be no consensus on the degree of aromaticity for the heterocyclic analogues of benzene with general formula $\mathrm{C}_{5} \mathrm{H}_{5} \mathrm{X}$ where $\mathrm{X}=\mathrm{CH}, \mathrm{SiH}, \mathrm{GeH}, \mathrm{N}, \mathrm{P}, \mathrm{As}, \mathrm{O}^{+}, \mathrm{S}^{+}, \mathrm{Se}^{+}$. The main aims of this investigation therefore are: (1) analysis of the influence of the heteroatom on the aromaticity of the cyclic conjugated system, and (2) investigation of the correlation of the indices both within a group of indices based on the same characteristics and among different groups. To address both items, one of the most elaborate studies known to us with respect to the number and type of indices is carried out.

A main focus of the paper is not only the evaluation of various indices but also the examination of their correlations. Kekulé ${ }^{66}$ originally constrained the use of the term aromaticity to only molecules that are "atomistically" constructed from $\mathrm{C}_{6}$ (benzenoid) units 
and he already infers that a degree of aromaticity should be derived by measuring some degree of similarity to benzene. Within this admittedly narrow range of molecules where the term aromaticity was originally used, good correlations are found between different indices or apparent inconsistency among indices can be resolved by careful statistical analysis. Kekulé also admitted not to know how to express the degree of similarity between molecules. However, his idea proved to be quite good as it has been shown by quantum similarity calculations which include for instance the Polansky index ${ }^{67}$ or later improvements using the

so-called NOEL similarity measures. ${ }^{68,69,70,71}$ Over the years, the term aromaticity has started to be used for much more diverse classes of molecules and inevitably the meaning of the term grew thinner. For example; one could define aromaticity as the retention of maintaining some key properties of benzene. Interestingly, the entire confusion or multidimensionality of aromaticity originates from the fact that one does not know exactly what properties are key properties and to what extent they should be retained in order to speak of aromaticity.

Therefore, in this paper we always specify what type of property of benzene lies at the heart of the aromaticity indices used. By adding to the claim that a molecule is aromatic also the underlying property for the index considered, the authors hope to reduce the confusion that the word aromaticity unavoidably seems to bring.

\section{METHODS AND COMPUTATIONAL DETAILS}

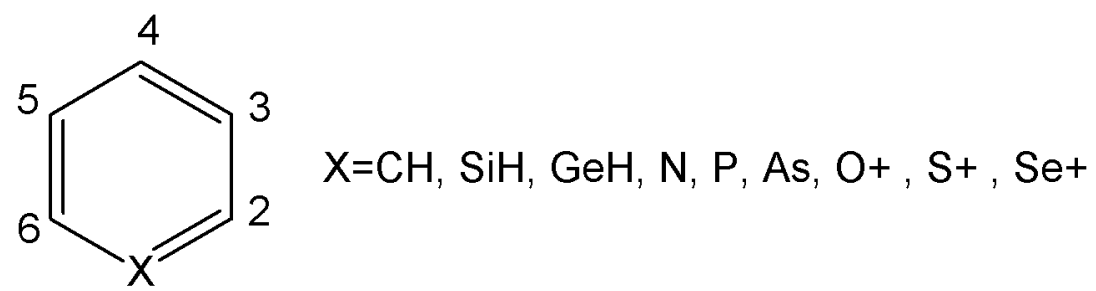

Scheme 1: Molecular structure of all molecules investigated. 
The structures of all examined molecules (Scheme 1) have been optimized using MøllerPlesset second order perturbation theory ${ }^{72}$ with the correlation-consistent triple-zeta basis set ${ }^{73}$ (MP2/cc-pvtz). It has been established ${ }^{74,75}$ that application of Pople basis sets augmented by diffuse functions (for example, $6-31++\mathrm{G}(\mathrm{d}, \mathrm{p})$ and $6-311++\mathrm{G}(\mathrm{d}, \mathrm{p})$ ) led to slight non-planarity of aromatic rings (including benzene) in the ground state. Correlation-consistent basis sets including the currently used cc-pvtz set do not exhibit this problem. No negative eigenvalues were found for the Hessian, confirming that all structures considered correspond to minima on the potential energy surface.

The different aromaticity indices are categorized based on the underlying property of benzene that they reflect.

\section{Structural indices}

The first group contains all structure related indices. Among the more often used indices is Bird's index. ${ }^{4}$ The common way to compute Bird's structural index relies on the statistical evaluation of the extent of variation of the bond orders in the ring. Bond orders can be obtained from experimental bond lengths using the Gordy equation ${ }^{76}$ with empirical constants. However, due to the lack of experimental data for the $\mathrm{C}-\mathrm{Si}, \mathrm{C}-\mathrm{Ge}, \mathrm{C}-\mathrm{As}$, and $\mathrm{C}-$ Se bond lengths, this equation cannot be used directly. Nevertheless, one can substitute other bond order definitions based on quantum chemically calculated data. Since this involves the density matrices of the molecule, the resulting alternative indices will be considered electronic structure aromaticity indices (see below). Typical for benzene is the bond length equalization which is also the inspiration of the HOMA index that also uses some empirical constants. ${ }^{10}$ However, the HOMA index was not used for estimation of the aromaticity in the current work, due to lack of suitable empirical constants for heavy atoms. Conformational flexibility of the rings can also be used as a structure based aromaticity index. Here it was studied by scanning each of the symmetry-unique endocyclic torsion angles over a range $\pm 30^{\circ}$ with steps 
of $5^{\circ}$. All remaining geometrical parameters were optimized at every step of the scan. For each molecule, the "softest" angle $\varphi$ with the smallest difference in energy between planar (torsion angle $0^{\circ}$ ) and the most non-planar (torsion angle $30^{\circ}$ ) geometries corresponding to the smallest out-of-plane ring deformation energy, $E(d e f)$ was used. Assuming a strictly harmonic energy dependence on the angle $\varphi$, it is possible to express the ring deformation energy as:

$$
E(\text { def })=A+K_{E} \cdot \varphi^{2}
$$

where $A$ and $K_{E}$ are coefficients of linear regression. The correlation coefficient was found to be excellent for the molecules considered with always $\mathrm{R}$ (corr) $>0.9999$. In the following, we use $K_{E}$ as the ring "rigidity constant" measuring the ring conformational flexibility. The population of the planar geometry of the ring was estimated based on the separation of the vibrational levels for the lowest ring out-of-plane vibration ${ }^{40,77}$. All input energies were computed at the MP2/cc-pvtz level. 


\section{Energetic indices}

Obviously, it is hard to strictly classify aromaticity indices and the deformation energy could also be considered to some extent to represent an energetic index. In the present work, indices are considered energetic only when they reflect reaction energies. Aromatic stabilization energies (ASE) $)^{1,28}$ were calculated at the MP2/cc-pvtz level using the homodesmotic reaction ${ }^{78}$ shown in Scheme 2. This scheme provides the most reliable results for a wide range of aromatic, non-aromatic and antiaromatic species ${ }^{3}$. All ASE calculations reported here include the zero-point energy (ZPE) correction.

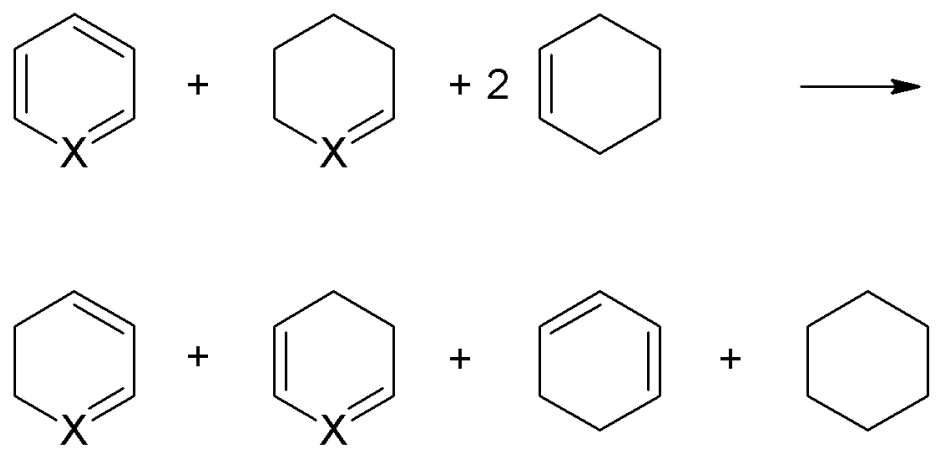

Scheme 2. Homodesmotic scheme for ASE calculation

\section{Electronic structure indices}

Electronic structure indices are defined to be those indices that are based on the electron distribution of the molecule or the molecular density matrix. Properties of the bond critical points $(\mathrm{BCP})$ of the carbon-heteroatom bonds and ring critical points $(\mathrm{RCP})$ for each molecule were calculated from the MP2/cc-pvtz electron density. Calculations were performed using the AIM $2000^{79}$ and $\mathrm{AimA} 1^{80}$ programs. Many other indices within this group in one way or another rely on the definition of a bond index or Shared-Electron Distribution Index (SEDI). ${ }^{81}$ The value of a SEDI depends on the technique used for describing the atom in the molecule (AIM) and it has recently been suggested that Bader's technique ${ }^{20}$ gives the most consistent values. ${ }^{82}$ SEDI can be computed over as many centers as desired giving rise to what is known 
as multicenter bond indices (MCBI). ${ }^{18}$ For calculations at the correlated level, the Müller ${ }^{83}$ or Buijse-Baerends approximation ${ }^{84}$ is used for higher order density matrices. The so-called sixcenter index $\Delta_{6}$, which corresponds to the highest order considered here, is given as:

$$
\Delta_{6}=\sum_{\Omega=1}^{6 !} \hat{\Gamma}_{\Omega}\left[\sum_{i, j, \ldots}^{N_{\alpha}}\left(\prod_{z}^{i, j \ldots} \eta_{z}^{1 / 6}\right) S_{i j}^{A} S_{j k}^{B} S_{k l}^{C} S_{l m}^{D} S_{m n}^{E} S_{n i}^{F}+\sum_{i, j, \ldots}^{N_{\beta}}\left(\prod_{z}^{i, j \ldots} \eta_{z}^{1 / 6}\right) S_{i j}^{A} S_{j k}^{B} S_{k l}^{C} S_{l m}^{D} S_{m n}^{E} S_{n i}^{F}\right]
$$

In this expression $S_{i j}^{A}$ corresponds to the atomic overlap integral between natural orbitals $i$ and $j$ over the domain of the atom $A$. $A$ to $F$ are the six atoms of the sixmembered ring. The natural orbitals have occupancies $\{\eta\}$ and the expression contains two equivalent terms but one specifically for the $N_{\alpha} \alpha$ spin orbitals and one for the $N_{\beta} \beta$ spin orbitals. The choice for using the roots of the occupation numbers in equation (2) is somewhat arbitrary but provided the use of roots, some simple sum rules apply that allow checking the accuracy of the $\mathrm{MCBI}^{85}$. Given the fact that atomic overlap integrals may need to be computed numerically, (non)adherence to the sum rule can show when better integrations are needed. Finally, $\hat{\Gamma}_{\Omega}$ is a permutation operator that creates all possible permutations of the labels $A$ L $F$. Expression (2) also leads, mutatis mutandis, to the 2-centre index $\Delta_{2}$ which coincides with the so-called delocalization indices as also introduced and used by Bader et al. $^{86}$. As will be shown in the results and discussion section, for some molecules the results of the QTAIM based MCBI give somewhat unexpected results. In this context, we also used the Mulliken based $\mathrm{MCBI}^{18}$ where a Mulliken projection operator is used ${ }^{87,88}$ (in this case only using Cartesian basis functions) and the Hirshfeld-I AIM ${ }^{89}$. The latter is of special interest because of the low basis set dependence ${ }^{90}$, which may be an issue with Mulliken's method ${ }^{91}$, and the fact that it was found that for organic molecules it reproduces very well the electrostatic potential on the molecular surface ${ }^{92}$. 
All MCBI have been computed at the MP2/cc-pvtz level of theory. This level of theory does not guarantee that the first order density matrix is positive semidefinite, which is obviously a problem when taking roots of the occupation numbers of the natural orbitals. However, only negative occupation numbers of very small magnitude have been found and we therefore opted to set those to exactly zero.

Once the $\Delta_{2}$ over the atoms in the ring are available, Bird's aromaticity index ${ }^{4-6}$ can be computed quite easily. In fact, inspired by earlier work, ${ }^{7,93,94,95}$ one of us has previously introduced an analogue of the HOMA index based on two centre bond indices (roughly equivalent to bond orders) where instead of bond lengths, bond indices are used. ${ }^{18,68,96}$ Again, parameters are necessary which makes them of little use here but one can use the standard deviation over all two centre bond indices (SDBI) in the ring as an indicator of the extent to which all bond indices between two consecutive atoms are equalized. Bird's Ia uses the same basic idea with the relation to SDBI given as:

$$
I_{a}=100\left(1-\frac{100}{K} \frac{S D B I}{\Delta_{2}^{a v}}\right)
$$

$\Delta_{2}^{a v}$ is the average $\Delta_{2}$ over the entire ring and $K$ is a constant based on a perfectly localized six-membered ring $(K=33.33)$.

Bond orders may also be calculated directly applying the Wiberg-Giambiagi-Mayer index ${ }^{97,98,99}$ from natural bond orbital $(\mathrm{NBO})^{100}$ calculations using the MP2/cc-pvtz wave function. These can then be used to obtain an NBO based alternative SDBI, henceforth described as NBO-SDBI. Likewise, an index $N B O-I_{a}$ can be computed. Note that the Wiberg-Giambiagi-Mayer index does not use Bader's QTAIM definition, causing possible disagreements in trends between the two flavors of SDBI or $I_{a}$.

Resonance structures and their contributions in the total electronic structure of molecules can also be used as an electronic structure aromaticity index. Here Natural Bond 
Orbital (NBO) theory ${ }^{100}$ and Natural Resonance Theory (NRT) ${ }^{101}$ was used to calculate them at the B3LYP/cc-pvtz level of theory for the MP2/cc-pvtz level geometry.

\section{Magnetic indices}

Benzene has already for long time $\mathrm{e}^{102,103}$ been known for sustaining a diatropic ring current and retention of such a ring current is often used as an indicator of aromaticity. In this work Nucleus-independent chemical shifts ${ }^{13}$ were calculated as the $\mathrm{zz}$ component of the magnetic shielding tensor in the point located $1 \AA$ above the center $\left(\mathrm{NICS}(1)_{\mathrm{zz}}\right)$ of the ring using the GIAO method ${ }^{104}$. Application of the zz-component of tensor instead of the average value has been claimed to describe aromaticity much more accurately. ${ }^{105,106}$ The NICS, however, do not by themselves reflect the existence of a true diatropic ring current as they are derived from the Biot-Savart integral that contains not only the current density. Visual inspection of a computed current density map can reveal whether it is a true ring current from which one can then optionally compute a NICS value. ${ }^{107}$ Usually, NICS values are not computed using such an integration scheme and having only a NICS value does not allow to draw conclusions of the underlying integrand. Hence, a NICS value is not proof of a ring current although in practice the conclusions inferred from NICS are compatible with what is deduced from current density maps. In order to avoid problems with the relationship between NICS and ring currents, in this work ring currents were computed at the RHF/cc-pvdz (using Cartesian basis functions) level of theory, using the geometries obtained at the MP2/cc-pvtz level. As ring current calculations are only routinely performed at the Hartree-Fock level, we opted for this level of theory. The basis set has been limited to cc-pvdz because of the need to involve coupled Hartree-Fock equations requiring lengthy orbital transformations and the need to compute the coefficients for the perturbed Hartree-Fock determinant. Moreover, the most important factors governing ring currents are the symmetry and the shape of the 
molecular orbitals. Symmetry does not depend on the basis set and the shape of the orbitals is not significantly altered by the number of basis functions employed. The algorithm used corresponds to the so-called continuous transformation of the origin current density (CTOCD) with diamagnetic zero (CTOCD-DZ), ${ }^{108,109,110,111}$ which is equivalent to the CGST method by Keith and Bader $^{12}$ and is also labeled as the ipsocentric method ${ }^{13,114}$. We always consider a magnetic field in the z-direction (perpendicular to the ring plane) and compute the perturbed orbitals using the first order coupled Hartree-Fock approach (FO-CHF). Ring currents are plotted on a grid in the $x y$ plane with a diatropic current represented by a counterclockwise circulation. Following Steiner et al. ${ }^{12,114}$, we also consider different molecular orbital contributions to the ring current.

All calculations have been performed using the Gaussian03, ${ }^{115}$ GAMESS US, ${ }^{116}$ NBO $5.0^{117}$ program packages and our own routines for the multicenter bond indices and ring current calculations.

\section{RESULTS AND DISCUSSION}

The results of the geometry optimizations reveal that all molecules under consideration have perfectly planar equilibrium geometries at the MP2/cc-pvtz level. This is in agreement with the known experimental data ${ }^{46,49,56,61}$. In what follows, results obtained using the different classes of indices will first be discussed followed by their the discussion.

\section{Structural indices}

In agreement with previous data ${ }^{37}$ all heterocycles under consideration have a significant degree of conformational flexibility. A change in the softest endocyclic torsion angle by $\pm 15^{\circ}$ results in an energy increase of less than $2 \mathrm{kcal} / \mathrm{mol}$. This means that only $68-85 \%$ of 
molecules possess a planar geometry of the ring at $298.15 \mathrm{~K}$. As was mentioned above, the conformational flexibility of a ring may be characterized by the out-of-plane deformation energy $\mathrm{E}(\mathrm{def})$ as well as by the rigidity constant $\mathrm{K}_{\mathrm{E}}$. Earlier $^{37,40}$ it has been demonstrated that these values correlate very well with the frequency of the lowest ring out-of-plane normal vibration for unsubstituted rings. Therefore, any of the indices $\mathrm{K}_{\mathrm{E}}, v_{\min }$, of $\mathrm{E}(\mathrm{def})$ can be used as a measure, and experimental measurement of this vibrational frequency can provide evidence for the ring flexibility at least for the compounds considered here.

Table 1. The "softest" endocyclic torsion angle with respect to ring out-of-plane deformations, value of the ring out-of-plane deformation energy ( $\mathrm{E}(\mathrm{def}), \mathrm{kcal} / \mathrm{mol})$, frequencies of the lowest ring out-of-plane normal vibration $\left(v_{\min }, \mathrm{cm}^{-1}\right)$, ring rigidity constant ( $\mathrm{K}_{\mathrm{E}}$ multiplied by 1000) and population of the planar geometry of ring at $300 \mathrm{~K}(\%)$ estimated from vibrational data.

\begin{tabular}{llcccc}
\hline Molecule & Torsion angle & E(def) & $v_{\min }$ & $\mathrm{K}_{\mathrm{E}}$ & Population \\
\hline $\mathrm{C}_{6} \mathrm{H}_{6}$ & $\mathrm{C} 1-\mathrm{C} 2-\mathrm{C} 3-\mathrm{C} 4$ & 7.22 & 405 & 8.45 & 85 \\
$\mathrm{C}_{5} \mathrm{H}_{5} \mathrm{SiH}$ & $\mathrm{Si1}-\mathrm{C} 2-\mathrm{C} 3-\mathrm{C} 4$ & 5.29 & 274 & 6.07 & 73 \\
$\mathrm{C}_{5} \mathrm{H}_{5} \mathrm{GeH}$ & $\mathrm{Ge1-C2-C3-C4}$ & 5.07 & 239 & 5.81 & 68 \\
$\mathrm{C}_{5} \mathrm{H}_{5} \mathrm{~N}$ & N1-C2-C3-C4 & 6.69 & 382 & 7.71 & 83 \\
$\mathrm{C}_{5} \mathrm{H}_{5} \mathrm{P}$ & P1-C2-C3-C4 & 4.94 & 297 & 5.71 & 76 \\
$\mathrm{C}_{5} \mathrm{H}_{5} \mathrm{As}$ & As1-C2-C3-C4 & 4.67 & 265 & 5.4 & 72 \\
$\mathrm{C}_{5} \mathrm{H}_{5} \mathrm{O}^{+}$ & $\mathrm{C} 2-\mathrm{C} 3-\mathrm{C} 4-\mathrm{C} 5$ & 6.50 & 380 & 7.49 & 82 \\
$\mathrm{C}_{5} \mathrm{H}_{5} \mathrm{~S}^{+}$ & S1-C2-C3-C4 & 5.21 & 296 & 6.04 & 75 \\
$\mathrm{C}_{5} \mathrm{H}_{5} \mathrm{Se}^{+}$ & Se1-C2-C3-C4 & 4.84 & 262 & 5.60 & 71 \\
\hline
\end{tabular}


Earlier $^{37-39,41}$ it was suggested that the conformational flexibility of rings could be used as a measure of aromaticity with higher flexibility reflecting lower aromaticity. Comparison of this property for the molecules under consideration (Table 1) indicates higher flexibility of the rings with a heavier heteroatom. The most flexible ring is observed for arsenobenzene and the selenopyrylium cation. The decrease of ring rigidity within every group has no exceptions and the difference between the $3^{\text {rd }}$ and $4^{\text {th }}$ row elements is much smaller than between the $2^{\text {nd }}$ and $3^{\text {rd }}$.

\section{Energetic indices}

As a representative of energetic indices, ASE are obtained from homodesmotic reactions as in scheme 2 and are reported in table 2.

Table 2. ASE values ( $\mathrm{kcal} / \mathrm{mol})$ of heterocyclic analogues of benzene.

\begin{tabular}{lccccc}
\hline & ASE & & ASE & & ASE \\
\hline $\mathrm{C}_{6} \mathrm{H}_{6}$ & 37.36 & $\mathrm{C}_{5} \mathrm{H}_{5} \mathrm{SiH}$ & 31.06 & $\mathrm{C}_{5} \mathrm{H}_{5} \mathrm{GeH}$ & 30.49 \\
$\mathrm{C}_{5} \mathrm{H}_{5} \mathrm{~N}$ & 32.65 & $\mathrm{C}_{5} \mathrm{H}_{5} \mathrm{P}$ & 30.21 & $\mathrm{C}_{5} \mathrm{H}_{5} \mathrm{As}$ & 29.05 \\
$\mathrm{C}_{5} \mathrm{H}_{5} \mathrm{O}^{+}$ & 29.06 & $\mathrm{C}_{5} \mathrm{H}_{5} \mathrm{~S}^{+}$ & 30.18 & $\mathrm{C}_{5} \mathrm{H}_{5} \mathrm{Se}^{+}$ & 29.31
\end{tabular}

The ASE values show relatively little variation among the different molecules which, at least according to these values, seems to indicate a similar degree of aromaticity over all molecules. There is generally a decrease in ASE going down the group to which the heteroatom belongs although the pyrylium cation seems to be an exception due to its lower value. ASE values for sila- and germabenzenes are slightly larger than those of the other rings containing "heavy" heteroatoms, although it is known that these compounds are less $\operatorname{stable}^{53,54}$ 


\section{Electronic structure indices}

The topology of the electron density in the molecules by itself is a rich source of information and Table 3 gives the electron density at the ring critical point (RCP) as well as key data on the bond critical point $(\mathrm{BCP})$ of the $\mathrm{C}-\mathrm{X}$ bond where $\mathrm{X}$ is the heteroatom.

Table 3. Electron density at the RCP $\left(\rho_{R C P}\right)$ and characteristics of bond critical point from QTAIM analysis (electron density $\rho_{B C P}$, Laplacian of electron density $\nabla^{2}$, ellipticity $\varepsilon$, QTAIM based SEDI $\Delta_{2}$ ) for the carbon-heteroatom bonds and QTAIM charges $q_{\text {QTAIM }}$ on the heteroatom.

\begin{tabular}{|l|l|l|l|l|l|l|l|}
\hline Molecule & \multicolumn{1}{|c|}{$\rho_{R C P}$} & Bond & $\rho_{B C P}$ & $\nabla^{2}$ & \multicolumn{1}{|c|}{$\varepsilon$} & $\Delta_{2}$ & $q_{\text {QTAIM }}$ \\
\hline $\mathrm{C}_{6} \mathrm{H}_{6}$ & 0.025 & $\mathrm{C} 2-\mathrm{C} 1$ & 0.3192 & -1.0517 & 0.194 & 1.17 & -0.036 \\
\hline $\mathrm{C}_{5} \mathrm{H}_{5} \mathrm{SiH}$ & 0.018 & $\mathrm{C} 2-\mathrm{Si1}$ & 0.1332 & 0.4297 & 0.326 & 0.68 & 2.628 \\
\hline $\mathrm{C}_{5} \mathrm{H}_{5} \mathrm{GeH}$ & 0.017 & $\mathrm{C} 2-\mathrm{Ge} 1$ & 0.1531 & 0.1897 & 0.182 & 0.98 & 1.394 \\
\hline $\mathrm{C}_{5} \mathrm{H}_{5} \mathrm{~N}$ & 0.027 & $\mathrm{C} 2-\mathrm{N} 1$ & 0.3417 & -0.9883 & 0.139 & 1.10 & -1.165 \\
\hline $\mathrm{C}_{5} \mathrm{H}_{5} \mathrm{P}$ & 0.020 & $\mathrm{C} 2-\mathrm{P} 1$ & 0.1721 & 0.1783 & 0.246 & 0.97 & 1.445 \\
\hline $\mathrm{C}_{5} \mathrm{H}_{5} \mathrm{As}$ & 0.018 & $\mathrm{C} 2-\mathrm{As} 1$ & 0.1619 & 0.0547 & 0.184 & 1.06 & 0.829 \\
\hline $\mathrm{C}_{5} \mathrm{H}_{5} \mathrm{O}^{+}$ & 0.027 & $\mathrm{C} 2-\mathrm{O} 1$ & 0.2990 & -0.0085 & 0.039 & 0.87 & -1.132 \\
\hline $\mathrm{C}_{5} \mathrm{H}_{5} \mathrm{~S}^{+}$ & 0.021 & $\mathrm{C} 2-\mathrm{S} 1$ & 0.2334 & -0.5315 & 0.255 & 1.17 & 0.628 \\
\hline $\mathrm{C}_{5} \mathrm{H}_{5} \mathrm{Se}^{+}$ & 0.019 & $\mathrm{C} 2-\mathrm{Se} 1$ & 0.1898 & -0.1808 & 0.248 & 1.14 & 0.873 \\
\hline
\end{tabular}

For the elements of the same group of the periodic system the electron density at the C$\mathrm{X}$ bond critical point uniformly decreases with the atomic number of the heteroatom. The electron density value for pyridine and the pyrylium cation is slightly higher than for benzene. 
Previous calculations at the B3LYP/6-311++G** level showed the same trend of the electron density topology derived properties as aromaticity criteria, with even larger differences. ${ }^{63}$

The degree of cyclic $\pi$-electron delocalization affects first of all the bond properties, and evidently the properties of the carbon-heteroatom $(\mathrm{C}-\mathrm{X})$ bonds might contain a considerable amount of information. Therefore, analysis of the characteristics of the corresponding bond critical points $(\mathrm{BCP})$ together with bond indices estimated by different methods (using Wiberg-Giambiagi-Mayer indices ${ }^{97-99}$ and two-center bond indices $\Delta_{2}{ }^{86}$ ) may provide essential information about the electronic structure of the molecules. Starting with the analysis of the topology of the electron density, it is worth noting that in general, QTAIM analysis does not separate $\sigma$ and $\pi$ electrons. Charge density is associated with the cumulative bond strength, so it cannot directly serve as a reliable estimate of only $\pi$-delocalization. Based on the values of the charge density at the bond critical points $(\mathrm{BCP})$ of the $\mathrm{C}-\mathrm{X}$ bonds (where $\mathrm{X}$ is the heteroatom) calculated for the considered species, the $2^{\text {nd }}$ row atoms are bonded to the carbon atoms considerably stronger than the $3^{\text {rd }}$ and $4^{\text {th }}$ row atoms. Also, the value of Laplacian of the electron density at the BCP reflects the degree of total ionicity of the corresponding bond. A positive value of the Laplacian for the $\mathrm{C}-\mathrm{X}$ bonds of "heavy" heteroatoms of the $4^{\text {th }}$ and $5^{\text {th }}$ groups indicates the absence of charge concentration between the atoms corresponding to highly ionic character of bonding. According to QTAIM theory the ellipticity value in the BCP is associated with the contribution of the $\pi$-component into the total bonding. It is zero for pure $\sigma$-bonds and increases with higher degree of $\pi$-bonding, achieving its maximum for a pure double bond. Therefore, its value, to some extent, is adequate to measure the degree of $\pi$-conjugation across the $\mathrm{C}-\mathrm{X}$ bond. An exceptionally low value is found for the ellipticity of the $\mathrm{C}-\mathrm{O}$ bond. This means that the $\mathrm{C}-\mathrm{O}$ bond in the pyrylium cation is almost purely a single $\sigma$-bond. However, this bond is very strong according to the value of the electron density at the $\mathrm{BCP}^{20}$. This means that cyclic conjugation is 
disrupted through the $\mathrm{C}-\mathrm{O}$ bond in the pyrylium cation. Conclusions concerning the extent of electron delocalization can be compared with the $\Delta_{2}$ values for these bonds, also shown in Table 3. The $\Delta_{2}$ values show that the $\mathrm{C}-\mathrm{O}$ bond has indeed a remarkably low value among all $\mathrm{C}-\mathrm{X}$ bonds with a value well below 1 . Orbital analysis of this value also reveals that it is of almost exclusively $\sigma$ nature. However, there are quite remarkable values for other molecules as well. The C-Si $\Delta_{2}$ value is the lowest over all values in Table 3 which is unexpected. The reason for this behavior can be traced back to the nature of Bader's QTAIM method. The Lewis structure that can be obtained using the delocalization indices is far from the results of the NBO analysis discussed further. This is exemplified by the atomic charges on the heteroatom which turn out to be quite outspoken especially for the Si atom.

Table 4 shows the values for the $S B D I, N B O-S D B I, I_{a}, N B O-I_{a}$ and $\Delta_{6}$ indices.

Table 4. MCBI derived indices (see text). $\Delta_{6}$ values have been scaled with respect to benzene which was given a value 100 .

\begin{tabular}{|c|c|c|c|c|c|}
\hline Molecule & SDBI & NBO-SDBI & $I_{a}$ & NBO-Ia & $\Delta_{6}$ \\
\hline $\mathrm{C}_{6} \mathrm{H}_{6}$ & 0.000 & 0.0 & 100.0 & 100.0 & 100.0 \\
\hline $\mathrm{C}_{5} \mathrm{H}_{5} \mathrm{SiH}$ & 0.037 & 0.124 & 20.7 & 73.2 & 71.3 \\
\hline $\mathrm{C}_{5} \mathrm{H}_{5} \mathrm{GeH}$ & 0.049 & 0.113 & 70.1 & 75.9 & 105.6 \\
\hline $\mathrm{C}_{5} \mathrm{H}_{5} \mathrm{~N}$ & 0.031 & 0.008 & 90.9 & 98.3 & 102.7 \\
\hline $\mathrm{C}_{5} \mathrm{H}_{5} \mathrm{P}$ & 0.042 & 0.064 & 69.1 & 86.5 & 64.4 \\
\hline $\mathrm{C}_{5} \mathrm{H}_{5} \mathrm{As}$ & 0.059 & 0.081 & 82.1 & 82.9 & 80.0 \\
\hline $\mathrm{C}_{5} \mathrm{H}_{5} \mathrm{O}^{+}$ & 0.170 & 0.149 & 56.1 & 67.6 & 48.0 \\
\hline $\mathrm{C}_{5} \mathrm{H}_{5} \mathrm{~S}^{+}$ & 0.081 & 0.045 & 92.2 & 90.6 & 82.8 \\
\hline $\mathrm{C}_{5} \mathrm{H}_{5} \mathrm{Se}^{+}$ & 0.090 & 0.058 & 91.9 & 88.0 & 90.4 \\
\hline
\end{tabular}


Coherent with the findings from Table 3, the QTAIM based data and NBO based data are quite divergent and even for a simple index like SDBI there is a total lack of correlation. The $\Delta_{6}$ values, also based on QTAIM, show large values for benzene, pyridine and the germanium substituted benzene with the latter even having the largest value. On the other hand, the Si substituted benzene has a very low value which is most likely related to the previous observation of a very highly charged $\mathrm{Si}$ atom. The pyrylium cation on the other hand is clearly marked as having the lowest value. Note also the dramatic effect of the QTAIM definition on $I_{a}$ for the Si compound. Although multicenter indices have been used quite successfully in many studies and performed the best according to Feixas et al. ${ }^{118}$ over a wide range of tests, one needs to be aware of the possible impact of the nature of the underlying AIM method. According to work by Heyndrickx et al. ${ }^{82}$, QTAIM technique outperforms the Hirshfeld-I method for non-bonded interactions. This, however, was based on a degree of fulfilling "expected trends". In the present case, this conclusion on aromaticity indices could be somewhat different.

To illustrate the impact of using a different AIM method, Table 5 shows atomic charges obtained using different AIM methods.

Table 5. Atomic charges obtained using different AIM methods.

\begin{tabular}{|c|c|c|c|}
\hline Molecule & $q_{\text {QTAIM }}$ & $q_{\text {Mulliken }}$ & $q_{\text {Hirshfeld }-I}$ \\
\hline $\mathrm{C}_{6} \mathrm{H}_{6}$ & -0.036 & -0.165 & -0.092 \\
\hline $\mathrm{C}_{5} \mathrm{H}_{5} \mathrm{SiH}$ & 2.628 & 0.412 & 1.288 \\
\hline $\mathrm{C}_{5} \mathrm{H}_{5} \mathrm{GeH}$ & 1.394 & 0.255 & 1.140 \\
\hline $\mathrm{C}_{5} \mathrm{H}_{5} \mathrm{~N}$ & -1.165 & -0.139 & -0.337 \\
\hline
\end{tabular}




\begin{tabular}{|c|c|c|c|}
\hline $\mathrm{C}_{5} \mathrm{H}_{5} \mathrm{P}$ & 1.445 & 0.079 & 0.281 \\
\hline $\mathrm{C}_{5} \mathrm{H}_{5} \mathrm{As}$ & 0.829 & 0.253 & 0.339 \\
\hline $\mathrm{C}_{5} \mathrm{H}_{5} \mathrm{O}^{+}$ & -1.132 & 0.023 & -0.013 \\
\hline $\mathrm{C}_{5} \mathrm{H}_{5} \mathrm{~S}^{+}$ & 0.628 & 0.474 & 0.594 \\
\hline $\mathrm{C}_{5} \mathrm{H}_{5} \mathrm{Se}^{+}$ & 0.873 & 0.608 & 0.726 \\
\hline
\end{tabular}

There are clearly large discrepancies between the different AIM charges depending on the method used. For the AIM charges, QTAIM in general gives more outspoken charges which is in line with previous findings by Fonseca Guerra et al. ${ }^{119}$. In fact, the atomic charges can be considered to be the first order MCBI and so it is clear that the higher order MCBI will also differ, most likely even more substantially. In case of the Mulliken method for example, the lowest $\Delta_{2}$ value is found for the pyrylium cation $\left(\Delta_{2}=1.18\right)$ and the Si compound has no remarkably small value $\left(\Delta_{2}=1.27\right)$. In fact, the value for benzene $\left(\Delta_{2}=1.31\right)$ is similar. Considering $\Delta_{6}$ values, the highest Mulliken values have been found for pyridine and benzene, with pyridine having a value slightly larger (at $102.2 \%$ of the benzene value). This is not exceptional for multicenter indices ${ }^{118}$. The lowest value $(78.3 \%)$ is found for the pyrylium cation whereas the Si compound has a value of 93.6\%. In fact, the three lowest values are always found for the cationic species (78.3, 78.2 and $81.6 \%$ for $\mathrm{O}, \mathrm{S}$ and Se respectively). Hirshfeld-I data for atomic charges lie between the Mulliken and Bader values. Comparison of QTAIM data in table 3 with the Mulliken and Hirshfeld-I data for e.g., pyridine versus benzene reveals that in case of Bader's method the C-X $\Delta_{2}$ is significantly smaller for pyridine whereas it is larger for the Mulliken based expression (1.43 versus 1.31$)$, a trend that is similar for Hirshfeld-I (1.42 versus 1.37). Such a dependence of the results on the AIM method obviously makes it hard to decide on what are the "correct" results. This means that 
one must take great care not only when choosing an index but in some cases also when choosing an underlying theoretical model. So beyond the question: what is the right index for studying aromaticity, comes a second question: what should be considered the better "flavor" of the same index if there are underlying variables such as the choice of a definition for the AIM.

Turning to NBO analysis, the special bond structure of the pyrylium cation could be expected to be also reflected in the resonance structures obtained from NRT analysis, whose results are shown in Scheme 3. Kekule structures provide the main contribution to the total electronic structure of the heterocycles. In general a decrease in the degree of aromaticity should be accompanied by a decrease in the weight of the Kekule structures. The lowest contribution of Kekule structures is found for the pyrylium cation (Scheme 3), where a significant contribution of zwitterionic resonance structures with a single $\mathrm{C}-\mathrm{O}$ bond $(\mathbf{7 d}-\mathbf{7 e})$ is observed. This indicates that the $\mathrm{C}-\mathrm{O}$ bonds in pyrylium cation are highly ionic. The low contribution of the Kekule type structures and hence low $\pi$ component of the $\mathrm{C}-\mathrm{O}$ bond does not contradict the results of the BCP analysis and $\Delta_{2}$ values. The C-O bond is quite strong but its contribution to the delocalization within the $\pi$-system of ring is rather low because of the dominantly $\sigma$ nature of the bond. Note that the Si compound is far from being an outlier when it comes to the Kekule weight, which stands in sharp contrast to some of the previous results based on QTAIM. 


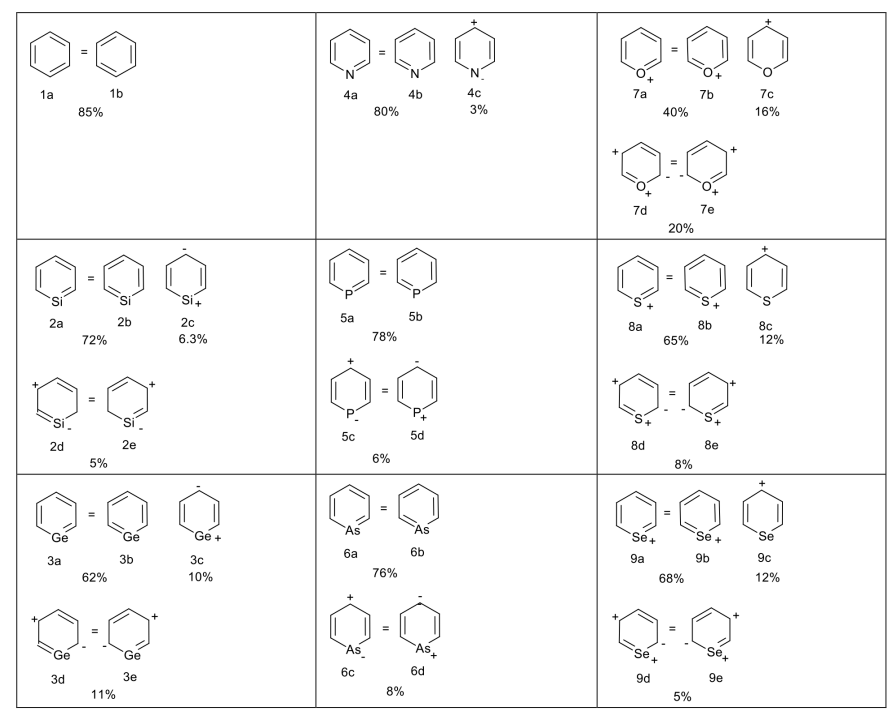

Scheme 3. Resonance structures providing maximal contributions into the total structure of heterocycles. Only structures with contributions higher than $3 \%$ are listed.

\section{Magnetic indices}

NICS are among the most popular aromaticity indices as they are a commonly available quantity from many ab initio programs and indeed often reflect the nature of the true current density map. Yet, as argued above, it is impossible to solidly derive from NICS a current density map which is obviously the key to assessing whether a current density map indeed reveals a ring current. Table 6 shows the NICS values for all molecules, computed as the $\mathrm{zZ}$ component of the NICS tensor at $1 \AA$ above the plane.

Table 6. $N I C S_{z z}(1)$ values (in ppm) of heterocyclic analogues of benzene.

\begin{tabular}{|c|c|c|c|c|c|}
\hline & $N I C S_{z z}(1)$ & & $N I C S_{z z}(1$ & & $N I C S_{z z}(1)$ \\
\hline$\overline{\mathrm{C}_{6} \mathrm{H}_{6}}$ & -30.4 & $\mathrm{C}_{5} \mathrm{H}_{5} \mathrm{SiH}$ & -25.5 & $\mathrm{C}_{5} \mathrm{H}_{5} \mathrm{GeH}$ & -25.2 \\
\hline $\mathrm{C}_{5} \mathrm{H}_{5} \mathrm{~N}$ & -30.2 & $\mathrm{C}_{5} \mathrm{H}_{5} \mathrm{P}$ & -28.0 & $\mathrm{C}_{5} \mathrm{H}_{5} \mathrm{As}$ & -26.8 \\
\hline $\mathrm{C}_{5} \mathrm{H}_{5} \mathrm{O}^{+}$ & -27.5 & $\mathrm{C}_{5} \mathrm{H}_{5} \mathrm{~S}^{+}$ & -28.9 & $\mathrm{C}_{5} \mathrm{H}_{5} \mathrm{Se}^{+}$ & -27.8 \\
\hline
\end{tabular}


The NICS values as computed here yield the most negative (and thus, as commonly considered, most aromatic) value for benzene with an only slightly less negative value for pyridine. In all cases the values grow less negative when going down in the same group of the periodic system. The pyrylium cation is again an exception as this species has the least negative value over all molecules in its group.

The specific magnetic properties of aromatic compounds are usually explained through the ring current associated with $\pi$-electron delocalization. ${ }^{102,103,120,121,122}$ Aromatic systems exhibit a diatropic $\pi$-ring current while antiaromatic rings possess a paratropic one. ${ }^{123}$ However, in both cases one requirement remains the same: the current should be cyclic. It is the presence of a true ring current that is used to establish whether a molecule is aromatic or not. The existence of a diatropic ring current in benzene is well documented. ${ }^{120-124}$ In case of the heterocyclic analogues to benzene, the situation is more complicated. Calculations of the ring current in pyridine demonstrated that it is only slightly weaker than in benzene. ${ }^{125,126}$ This agrees well with estimates based on NMR spectral properties of aromatic hydrogens. ${ }^{127,128}$ Calculations of integrated ring susceptibility ${ }^{126}$ indicated weakening of the ring current in phospha- and arsenobenzenes as compared to pyridine. Therefore, taking into account the values of the aromaticity indices it is possible to expect the presence of a clear diatropic ring current in all heterocycles under consideration. Figure 1 shows the obtained induced current maps for all electrons in a plane parallel to and $1 \mathrm{a}_{0}$ above the molecular plane. 


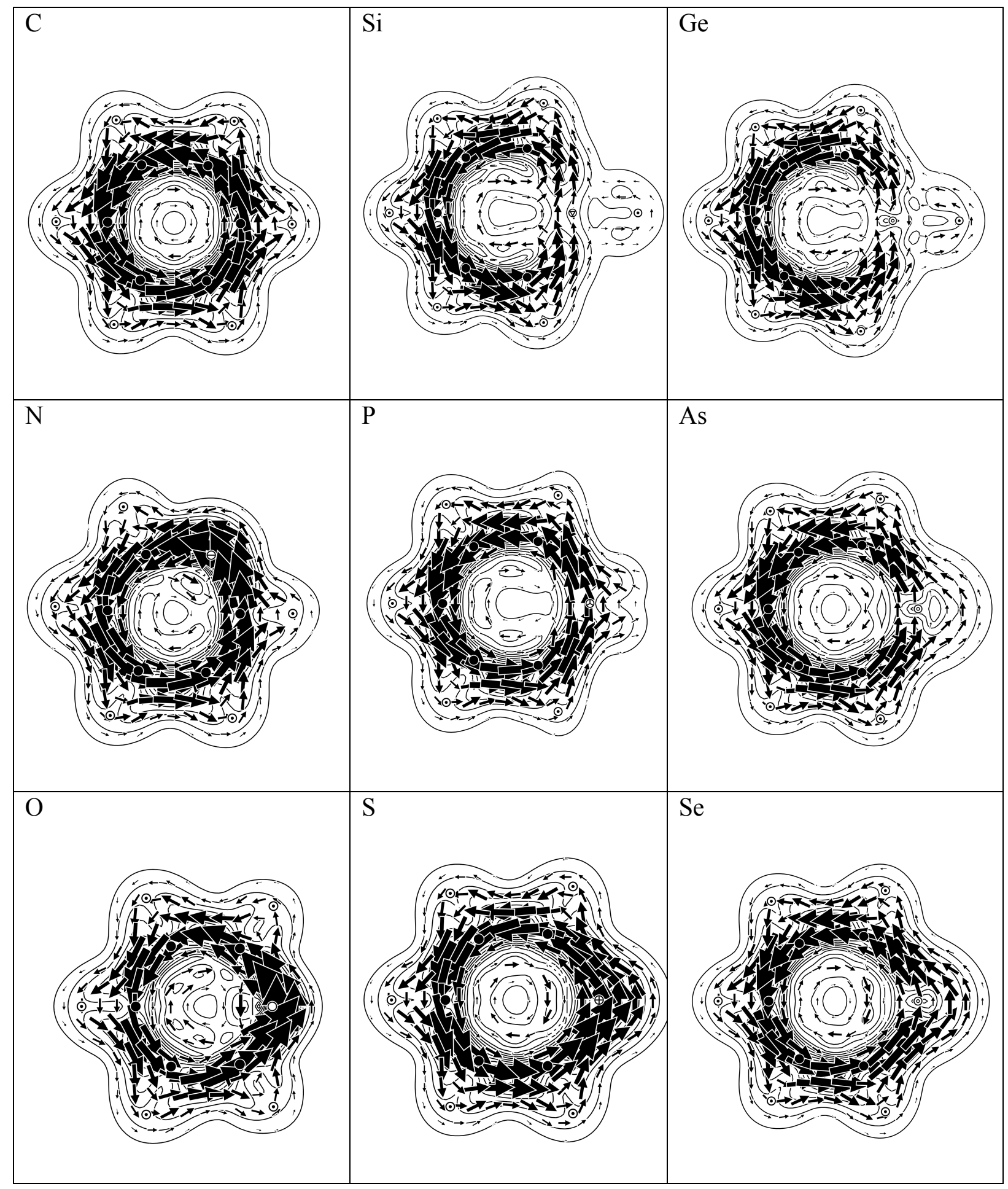

Fig.1. Map of the HF/cc-pvdz//MP2/cc-pvtz induced current densities by a perpendicular magnetic field. Contributions of all electrons are shown, plotted at a height of 1 $\mathrm{a}_{0}$ above the molecular plane with a diatropic ring current represented through 
counterclockwise circulation. Positions of nuclei are marked with Dalton symbols except for fourth period elements where a generic symbol is used.

The ring current of pyridine exhibits some asymmetry compared to benzene (Fig. 1). A considerably higher current intensity is observed in the area of the nitrogen atom. Similar results were obtained for the other heterocyclic analogues of benzene containing heteroatoms of group IV of the Periodic System. In the case of silicon and especially germanium some interruption of the ring current near the heteroatom seems to appear. Nevertheless, in both cases a strong current is found in the carbon part of heterocycle. Usually the investigation of a $\pi$-ring current is based on the calculation of the current in the plane located $1 \mathrm{a}_{0}$ above the plane of the ring. In this case mainly the $\pi$-component of the ring current is taken into account although a $\sigma$ contribution cannot be excluded. Heavier atoms possess considerably bigger atomic $^{\text {radii }}{ }^{129}$ and possibly, the $\pi$-ring current in heterocycles containing heteroatoms of the third and fourth periods of periodic system might be better reflected using a different plane. Indeed, when plotting the current density vectors in a plane higher above the molecular plane, a more uniform looking ring current was found. In a previous study on inorganic monocycles including rings with combinations of atoms of different periods in the periodic system, De Proft et al. examined the ring currents by plotting them on planes at different heights above and parallel to the molecular plane $\mathrm{e}^{130}$ and choosing some optimal plane. We followed a similar reasoning and computed the induced current density vector in the middle of each chemical bond in the ring and at different heights above this same set of points. This was done for both the total current density and that from the three highest $\pi$ orbitals separately. The choice for the midpoints of the bonds is based on the fact that very large current density vectors may appear in the direct vicinity of the heteroatoms whereas they are not directly related to a ring current. For both cases, total and $\pi$ current density, the modulus of the current 
density vector was computed in the midpoint of each bond (or above it when considering different heights of the plotting plane above the molecular plane) and the average over these points in all 6 bonds computed. For all molecules, it was found that due to the presence of (at least) $4 \mathrm{C}$-C bonds, the highest average was found for the plane $1 \mathrm{a}_{0}$ above the molecular plane. For an individual $\mathrm{C}-\mathrm{X}$ bond, the maximum can be located at a larger distance, e.g., in a plane $1.4 \mathrm{a}_{0}$ above the molecular plane for the selenium compound. This makes a quantitative discussion biased by how exactly the plane used for comparison is defined. However, in any case, there is a clear diatropic $\pi$ ring current as main contributor to the total ring current with a very minor $\sigma$ contribution. Taking the average described above in the plane $1 \mathrm{a}_{0}$ above the molecular plane, the results shown in table 7 indicate that the largest value (denoted $J_{a v}$ ) occurs for benzene with a very similar value for pyridine. The pyrylium cation exhibits the smallest value among the molecules containing a second row element as heteroatom but overall the differences are fairly small.

Table 7. $J_{a v}$ values (in au) computed over all points $1 \mathrm{a}_{0}$ above the midpoints of the chemical bonds in the 6-membered rings.

\begin{tabular}{cccccc}
\hline & $J_{a v}$ & & $J_{a v}$ & & $J_{a v}$ \\
\hline $\mathrm{C}_{6} \mathrm{H}_{6}$ & 0.069 & $\mathrm{C}_{5} \mathrm{H}_{5} \mathrm{SiH}$ & 0.051 & $\mathrm{C}_{5} \mathrm{H}_{5} \mathrm{GeH}$ & 0.052 \\
$\mathrm{C}_{5} \mathrm{H}_{5} \mathrm{~N}$ & 0.068 & $\mathrm{C}_{5} \mathrm{H}_{5} \mathrm{P}$ & 0.059 & $\mathrm{C}_{5} \mathrm{H}_{5} \mathrm{As}$ & 0.058 \\
$\mathrm{C}_{5} \mathrm{H}_{5} \mathrm{O}^{+}$ & 0.056 & $\mathrm{C}_{5} \mathrm{H}_{5} \mathrm{~S}^{+}$ & 0.059 & $\mathrm{C}_{5} \mathrm{H}_{5} \mathrm{Se}^{+}$ & 0.057 \\
\hline
\end{tabular}

The retention of a ring current in all molecules, as depicted above, is in very good agreement with the findings concerning the NICS(1) zz (Table 6). In recent work, Havenith et al. ${ }^{131}$ used the maximum modulus over all $\pi$ current density vectors in a $\left(3 \mathrm{a}_{0} \times 3 \mathrm{a}_{0}\right)$ plane para to the heteroatom and contained in the symmetry plane orthogonal to the molecular plane. In their 
case, the heteroatom corresponds to a transition metal resulting in the finding that different transition metals can substantially influence this value. In the present set of molecules, we found that this effect was much smaller (e.g., 0.072 for benzene versus 0.066 for silabenzene representing respectively the highest and lowest values in table 7) and the conclusions obtained from all data are very comparable to those obtained from table 7.

\section{Correlation of aromaticity indices}

Benzene is without doubt the most emblematic molecule in the context of aromaticity. This species unites all characteristics of an aromatic molecule and is the natural reference for assessing aromaticity. The problem with the use of the word aromaticity beyond (polyaromatic) hydrocarbons is that depending on the typical benzene property used to assess a degree of aromaticity, a different ranking within a set of molecules may be obtained. This has given rise to the idea of aromaticity being a multidimensional property. ${ }^{29,30}$ Such idea is naturally a consequence of modern attempts to express a concept like aromaticity on a quantitative numerical scale whereas the concept itself is not properly defined. Claims such as one molecule being more aromatic than another are obviously biased. In some cases, notably in the case of polyaromatic hydrocarbons, ${ }^{32-34}$ some indices can be reconciled through careful analysis, in other cases there is genuine divergence. But even such divergence is sometimes easily understood as for example, for a true ring current, electron delocalization is a necessary but not a sufficient requirement. For the current set of molecules, Table 8 gives the correlation coefficients between the different indices. It appears that sometimes good correlations are found but there are also many cases of poor correlation. 
Table 8. Correlation coefficients $\left(\mathrm{R}^{2}\right)$ between indices calculated for considered molecules. Where relevant, values in parenthesis correspond to data excluding the pyrylium cation.

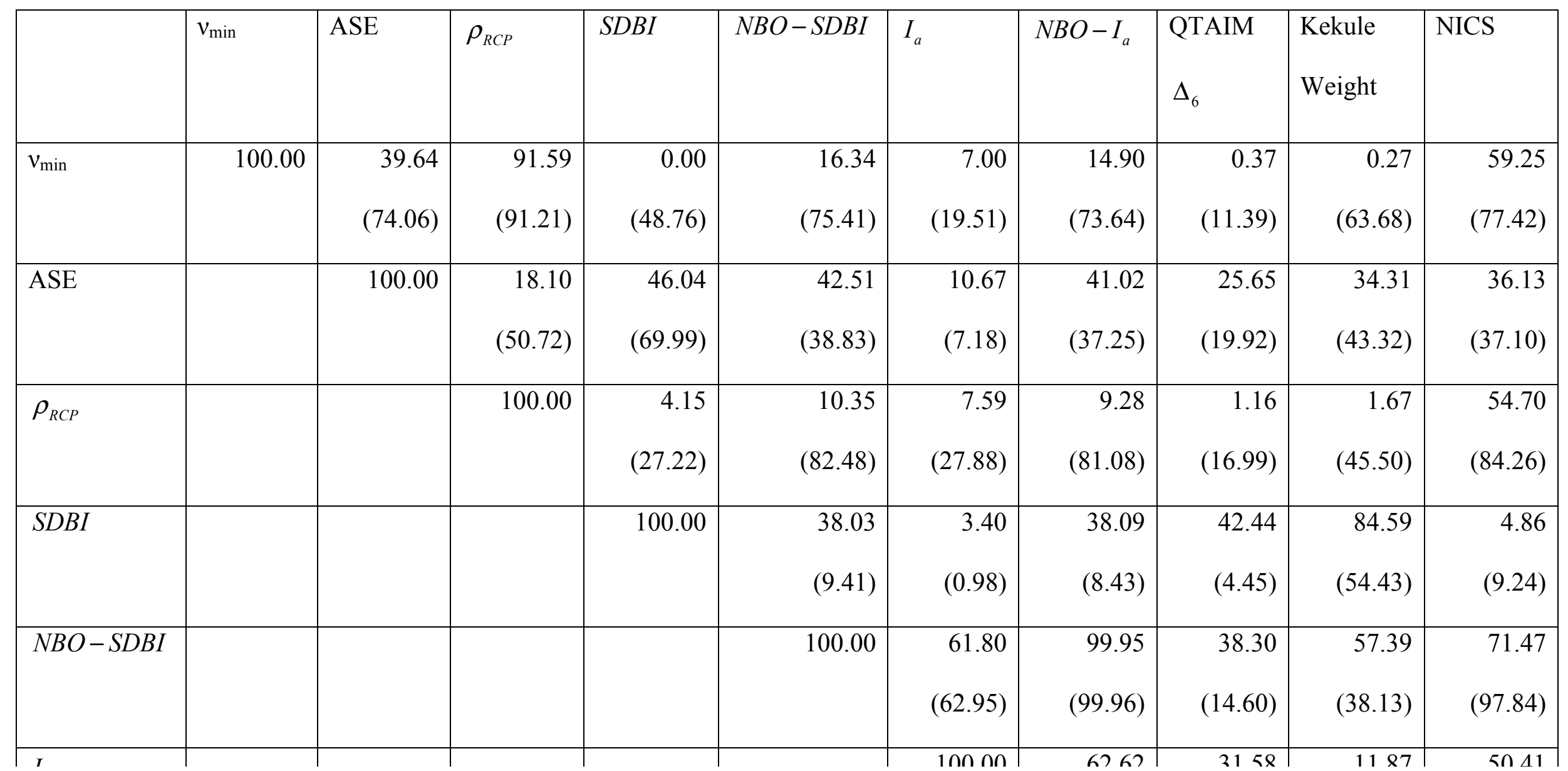




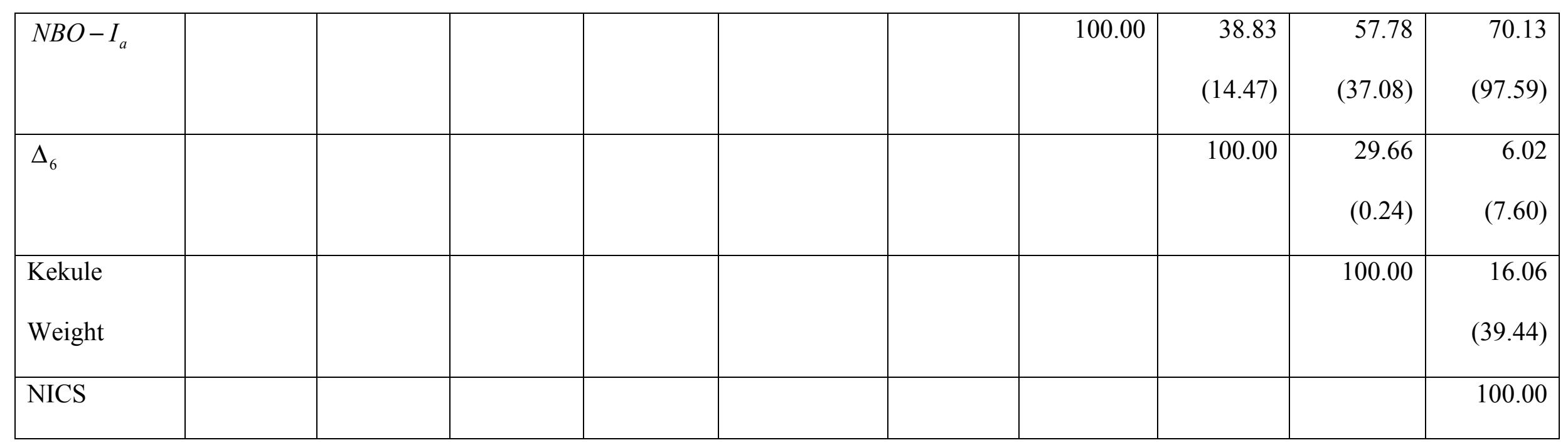


The different properties typical for benzene do not manifest themselve: anymore for the other molecules. This is exemplified by the data displayed in $\mathrm{Ta}$ present case seems to be a genuine case of multidimensionality, as was previously : for e.g., metallic clusters. ${ }^{35}$ However, rather than a physical phenom multidimensionality stems from the different interpretations of the concept of at One could attempt to interpret the higher correlation coefficients in Table 8 be example, the geometry of a molecule is linked intimately to its electronic structure tl Hamiltonian but despite this relationship, it is far from trivial to express more prs grounds for a favorable correlation. Table 8 also has correlation coefficients exc pyrylium cation because of its outlier nature for many indices. Still, as the table : lack of correlation remains in many cases and cases where it does improve signific: still do not result in values above $80 \%$ which can be considered a lower limit significant importance to the correlation given the number of molecules.

A numerical investigation based on the correlation coefficients as shown $\mathrm{i}$ might be too ambitious and one could settle with indices pointing "in the san direction" when it comes to comparing degrees of aromaticity. It is therefore worth whether there is similarity in ranking of the different molecules with respec aromaticity. Figure 2 shows such a ranking. The most aromatic molecule accord index considered is ranked number 1 and the least aromatic is ranked number 9. 7 clearly shows that different indices can also simply result in a different ranki molecules. 


$\begin{array}{rrrrrrrrrrr} & v_{\text {min }} & \text { ASE } & \rho_{\text {RCP }} & \text { SDBI } & \begin{array}{c}\text { NBO- } \\ \text { SDBI }\end{array} & I_{a} & \text { NBO- } I_{a} & \Delta_{6} & \begin{array}{l}\text { Kekule } \\ \text { Weight }\end{array} & \text { NICS } \\ \mathrm{C}_{6} \mathrm{H}_{6} & 1 & 1 & 3 & 1 & 1 & 1 & 1 & 3 & 1 & 1 \\ \mathrm{C}_{5} \mathrm{H}_{5} \mathrm{SiH} & 6 & 3 & 7 & 3 & 8 & 9 & 8 & 7 & 5 & 8 \\ \mathrm{C}_{5} \mathrm{H}_{5} \mathrm{GeH} & 9 & 4 & 9 & 5 & 7 & 6 & 7 & 1 & 8 & 9 \\ \mathrm{C}_{5} \mathrm{H}_{5} \mathrm{~N} & 2 & 2 & 1 & 2 & 2 & 4 & 2 & 2 & 2 & 2 \\ \mathrm{C}_{5} \mathrm{H}_{5} \mathrm{P} & 4 & 5 & 5 & 4 & 5 & 7 & 5 & 8 & 3 & 4 \\ \mathrm{C}_{5} \mathrm{H}_{5} \mathrm{As} & 7 & 9 & 7 & 6 & 6 & 5 & 6 & 6 & 4 & 7 \\ \mathrm{C}_{5} \mathrm{H}_{5} \mathrm{O}^{+} & 3 & 8 & 1 & 9 & 9 & 8 & 9 & 9 & 9 & 6 \\ \mathrm{C}_{5} \mathrm{H}_{5} \mathrm{~S}^{+} & 5 & 6 & 4 & 7 & 3 & 2 & 3 & 5 & 7 & 3 \\ \mathrm{C}_{5} \mathrm{H}_{5} \mathrm{Se}^{+} & 8 & 7 & 6 & 8 & 4 & 3 & 4 & 4 & 6 & 5\end{array}$

Fig. 2. Comparison of the ranking of molecules based on the different indices. For each descriptor, a molecule is assign a number between 1 (most aromatic) and 9 (least aromatic) and the color coding shows in a simple fashion differences in the ranking between all descriptors (green $=$ most aromatic, red=least aromatic).

This very clearly shows that any claim on relative aromaticity of molecules is extremely dependent on the property considered and we have not found a clear rationale as how to reconcile the different indices from a meaningful physical perspective. Figure 2 very clearly shows that a claim on the aromatic nature of a molecule depends critically on what property is considered to measure a degree of aromaticity. This is clearly not satisfactory from a scientific point of view and we therefore strongly suggest to very explicitly mention what property was used to derive a degree of aromaticity. Even within a set of indices of the same nature (structural, magnetic, etc.), Table 8 and Figure 2 also clearly show that one must still be careful not to draw overly general conclusions stressing even more that the index used should be very well described.

One could suggest to use some consensus approach to arrive to a degree of aromaticity. Taking the geometric average of the rank of a molecule over all indices used in figure 2 , the conclusion is that the most aromatic molecule is benzene and the least aromatic one is the arsenic analogue. According to this consensus approach, the pyrylium cation is the second 
least aromatic species although the difference this molecule and the arsenic compound is small.

\section{CONCLUSIONS}

The degree of aromaticity of six-membered monoheterocycles with IV - VI group heteroatoms $\left(\mathrm{C}_{6} \mathrm{H}_{5} \mathrm{X}\right.$, where $\left.\mathrm{X}=\mathrm{SiH}, \mathrm{GeH}, \mathrm{N}, \mathrm{P}, \mathrm{As}, \mathrm{O}^{+}, \mathrm{S}^{+}, \mathrm{Se}^{+}\right)$was analyzed using different aromaticity indices based on structural, magnetic, energetic and electronic properties of the aromatic rings. All indices indicate significant aromaticity of all heterocycles under consideration. However, considerable inconsistency between the different indices was found.

The pyrylium cation represents a clear exception from all correlations between aromaticity indices. According to most indices, except the structural-dynamic ones, the $\pi$ system in this molecule is less aromatic than in the thio- and selenopyrylium cations. Topological analysis of the bond critical points for the $\mathrm{C}-\mathrm{O}$ bonds indicates a strong ionicity of this bond with low contribution of the $\pi$-component into total bonding. This agrees well with considerably smaller values of Wiberg bond order and two-centre bond index for this bond as compared to other carbon-heteroatom bonds. Calculation of contributions of different resonance structures into the total structure of the pyrylium cation demonstrates considerably lower weight of Kekule structures as compared to other heterocycles.

Ring current plots reveal the existence of a ring current in all molecules, in agreement with what could be anticipated from NICS values. To facilitate examination of the ring currents a new scaling is introduced for the plane on which the current is plotted. This allows to take into account some non-planarity of ring current around heteroatoms of third and forth periods of Periodic Table caused by the large size of the heteroatom as compared to neighboring carbons. 
The most important conclusion is that one should always very clearly describe exactly which index is used to assess "aromatic" character and provide the details how the index was computed. The so-called multidimensionality of aromaticity is to large extent also due to the use of the same term to cover the similarity of different properties to benzene as an archetype.

\section{ACKNOWLEDGEMENTS}

Support for this study has been provided by the NSF-EPSCoR Award \#: 362492190200-01 \NSFEPS-0903787. P.B. acknowledges financial support of FWO-Vlaanderen. Calculations were partly carried out using the Stevin Supercomputer Infrastructure at Ghent University.

\section{GRAPHICAL ABSTRACT}

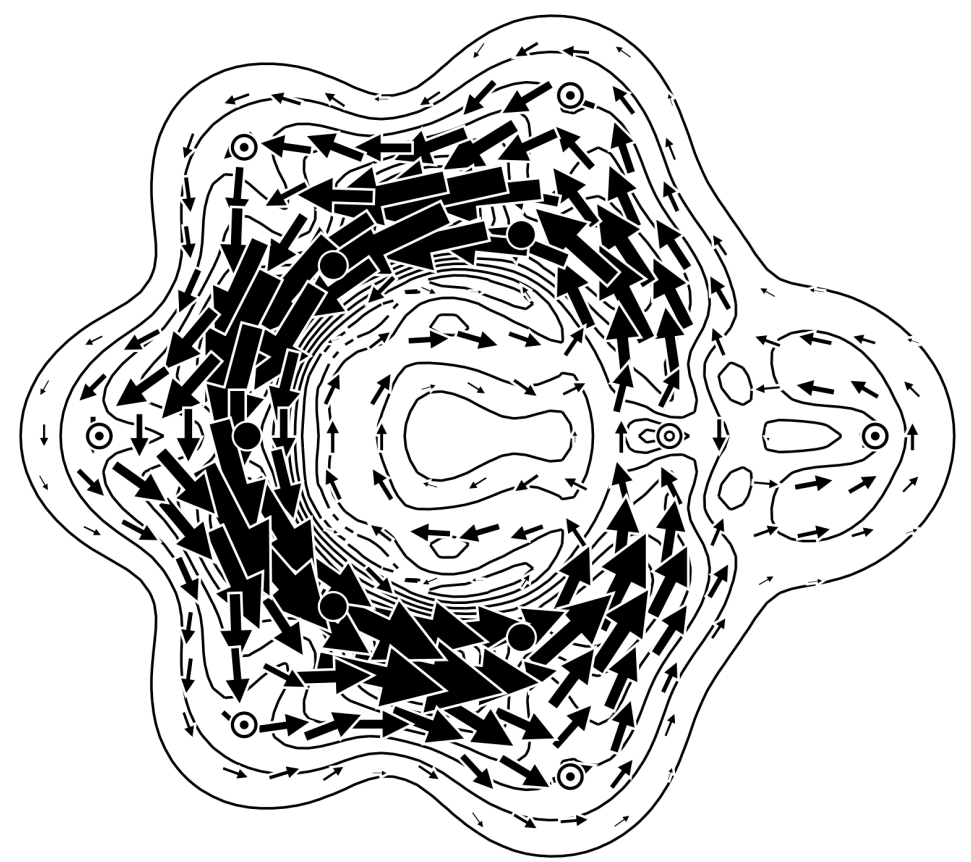

Heterocyclic analogues of benzene have been investigated using a wide range of structural, energetic, magnetic and electronic aromaticity descriptors. 


\section{References}

1 V. I. Minkin, M. N. Glukhovtsev, B. Y. Simkin, Aromaticity and Antiaromaticity, Wiley, New York, 1994.

2 D. Lloyd, J. Chem. Inf. Comp. Sci., 1996, 36, 442.

3 M. K. Cyranski, Chem. Rev., 2005, 105, 3773.

4 C. W. Bird, Tetrahedron, 1992, 48, 335.

5 C. W. Bird, Tetrahedron, 1986, 42, 89.

6 C. W. Bird, Tetrahedron, 1992, 48, 335.

7 A. F. Pozharskii, Chem. Heterocycl. Compd., 1985, 21, 717.

8 J. Kruszewski, T. M. Krygowski, Bull. Acad. Polon. Sci. Ser. Sci. Chim., 1972, $20,907$.

9 J. Kruszewski, T. M. Krygowski, Tetrahedron Lett., 1972, 36, 3839.

10 T. M. Krygowski, J. Chem. Inf. Comp. Sci., 1993, 33, 70.

11 J. Hoarau, in Localization and Delocalization in Quantum Chemistry, ed. O. Chalvet, R.

Daudel, S. Diner, J.P,Malrieu, Vol. 1, Reidel, Dordrecht, 1975.

12 H. J. Dauben, J. D. Wilson, J. L. Laity, J. Am. Cem. Soc., 1968, 90, 811.

13 P. v. R.Schleyer, C. Maerker, A. Dransfeld, H. Jiao, N. J. R. van Eikema Hommes, J. Am. Chem. Soc., 1996, 118, 6317.

14 Z. Chen, C. S. Wannere, C. Corminboeuf, R. Putcha, P. v. R. Schleyer, Chem. Rev., 2005, 105,3842 .

15 J. Poater, M. Duran, M. Sol, B. Silvi, Chem. Rev., 2005, 105, 3911.

16 J. Poater, X. Fradera, M. Duran, M. Sola, Chem.-Eur. J., 2003, 9, 400.

17 E. Matito, M. Duran, M. Sola, J. Chem. Phys., 2005, 122, 014109.

18 P. Bultinck, R. Ponec, S. Van Damme, J. Phys. Org. Chem., 2005, 18, 706.

19 P. Bultinck, M. Rafat, R. Ponec, R. Carb-Dorca, P. Popelier, J. Phys. Chem. A, 2006, 110, 7642. 
20 R. F. W Bader, Atoms In Molecules. A Quantum Theory, ClarendronPress: Oxford, U.K., 1990.

21 P. L. Popelier, Atoms in Molecules: An Introduction, Prentice Hall, London, 2000.

22 S. T. Howard, T. M. Krygowski, Can. J. Chem., 1997, 75, 1174.

23 M. Palusiak, T. M. Krygowski, Chem.-Eur. J., 2007, 13, 7996.

24 M. Mandado, P. Bultinck, M. J. Gonzalez Moa, R. A. Mosquera Casto, Chem. Phys. Lett., 2006, 433, 5 .

25 C. F. Matta, J . Hernandez-Trujillo, J. Phys. Chem. A, 2003, 107, 7496.

26 S. I. Kotelevskii, O. V. Prezhdo, Tetrahedron, 2001, 57, 5715.

27 M. K. Cyranski, T. M. Krygowski, A. R. Katritzky, P. v. R. Schleyer, J. Org. Chem., 2002, 67, 1333.

28 P. v. R. Schleyer, H. Jiao, Pure\&Appl. Chem., 1996, 68, 209.

29 A. R. Katritzky, P. Barczynski, G. Musumarra, D. Pisano, M. Szafran, J. Am. Chem. Soc., 1989, 111, 7.

30 K. Jug, D. C. Oniciu, A. R. Katritzky, Chem. Rev., 2001, 101, 1421.

31 R. Ponec, P. Bultinck, A. Gallegos Saliner, J. Phys. Chem. A, 2005, 109, 6606.

32 S. Fias, S. Van Damme, P. Bultinck, J. Comput. Chem., 2008, 29, 358.

33 S. Fias, P. Fowler, J. L. Delgado, U. Hahn, P. Bultinck, Chem.-Eur. J., 2008, 14, 3093.

34 S. Fias, S. Van Damme, P. Bultinck, J. Comput. Chem., 2010, 31, 2286.

35 P. Bultinck, S. Fias, M. Mandado, R. Ponec, in Aromaticity and Metal Clusters, Ed. Pratim K. Chattaraj, Taylor and Francis, 2010, pp. 245-270.

36 F. Dijkstra, J. H. van Lenthe, Int. J. Quantum Chem., 1999, 74, 213.

37 O. V. Shishkin, K. Yu. Pichugin, L. Gorb, J. Leszczynski, J. Mol. Struct., 2002, 616, 159.

38 M. V. Zhigalko, O. V. Shishkin, L. Gorb, J. Leszczynski, J. Mol. Struct., 2004, 693, 153.

39 M. V. Zhigalko, O. V. Shishkin, J. Struct. Chem., 2006, 47, 823. 
40 O. V. Shishkin, L. Gorb, J. Lesczynski, Chem. Phys. Lett., 2000, 330, 603.

41 O. V. Shishkin, I. V. Omelchenko, M. V. Krasovska, R. I. Zubatyuk, L. Gorb, J. Leszczynski, J. Mol. Struct., 2006, 791, 158.

42 W. Dong, H. Wang, Q. Ge, L. Wang, Struct. Chem., 2007, 18, 593.

43 M. K. Cyranski, P. v. R. Schleyer, T. M. Krygowski, H. Jiao, G. Hohlneicher, Tetrahedron, 2003, 59, 1657.

44 A. T. Balaban, D. C. Oniciu, A. R. Katritzky, Chem. Rev., 2004, 104, 2777.

45 T. M. Krygowski, M. K. Cyranski, Chem. Rev., 2001, 101, 1385.

46 A. J. Ashe, III, Acc. Chem. Res., 1978, 11, 153.

47 G. Frison, A. Sevin, N. Avarvari, F. Mathey, P. Le Floch, J. Org. Chem., 1999, 64, 5524.

48 W. C. Herndon, Tetrahedron Lett., 1979, 35, 3283.

49 K. K. Baldridge, M. S. Gordon, J. Am. Chem. Soc., 1988, 110, 4204.

50 R. Salcedo, J. Mol. Struct. (THEOCHEM), 2004, 674, 125.

51 L. Nyulaszi, Chem. Rev., 2001, 101, 1229.

52 T. L. T. Parreira, S. E. Galembeck, J. Mol. Struct. (THEOCHEM), 2006, 760, 59.

53 V. Ya. Lee, A. Sekiguchi, M. Ichinohe, N. Fukaya, J. Organometallic Chem., 2000, 611, 228.

54 N. Tokitoh, Bull. Chem. Soc. Jpn., 2004, 77, 429.

55 K. Wakita, N. Tokitoh, R. Okazaki, S. Nagase, Angew. Chem. Int. Ed., 2000, 39, 634.

56 N. Nakata, N. Takeda, N. Tokitoh, J. Am. Chem. Soc., 2002, 124, 6914.

57 M. S. Gordon, P. Boudjouk, F. Anwari, J. Am. Chem. Soc., 1983, 105, 4972.

58 K. K. Baldridge, O. Uzan, J. M. L. Martin, Organometallics, 2000, 19, 1477.

59 P. v. R. Schleyer, F. Puhlhofer, Org. Lett., 2002, 4, 2873.

60 J. C. Santos, P. Fuentealba, Chem. Phys. Lett., 2007, 443, 439.

61 I. Yavari, S. Dehghan, M. Nikpoor-Nezhati, Phosph. Sulf. Silicon Rel. El., 2003, 178, 869. 
62 U. D. Priyakumar, G. N. Sastry, J. Org. Chem., 2002, 67, 271.

63 M. Z. Kassaee, N. Jalalimanesh, S. M. Musavi, J. Mol. Struct. (THEOCHEM), 2007, 816, 153.

64 A. A. Ebrahimi, R. Ghiasi, C. Foroutan-Nejad, J. Mol. Struct. (THEOCHEM), 2010, 941, 47.

65 S. N. Pieniazek, F. R. Clemente, K. N. Houk, Angew. Chem. Int. Ed., 2008, 47, 7746.

66 A. Kekulé, Lehrbuch der Organischen Chemie, Zweiter Band, Ferdinand Enke Verlag: Erlangen, 1866.

67 O. Polansky, G. Derflinger, Int. J. Quant. Chem., 1967, 1, 379.

68 P. Bultinck, R. Ponec, A. Gallegos, S. Fias, S. Van Damme, R. Carbó-Dorca, Croat. Chem. Acta, 2006, 79, 363.

69 P. Bultinck, R. Ponec, R. Carbó-Dorca, J. Comput. Chem., 2007, 28, 152.

70 J. Cioslowski, E. D. Fleischmann, J. Am. Chem. Soc., 1991, 113, 64.

71 J. Cioslowski, E. D. Fleischmann, Croat. Chem. Acta, 1993, 66, 113.

72 C. Møller, M. S. Plesset, Phys. Rev., 1934, 46, 618.

73 R. A. Kendall, T. H. Dunning Jr., R. J. Harrison, J. Chem. Phys., 1992, 96, 6796.

74 O. V. Shishkin, L. Gorb, A. V. Luzanov, M. Elstner, S. Suhai, J. Leszczynski, J. Mol. Struct. (THEOCHEM), 2003, 625, 295.

75 D. Moran, A. C. Simmonett, F. E. Leach, W. D. Allen, P. v. R. Schleyer, H. F. Schaefer, J. Am. Chem. Soc., 2006, 128, 9342.

76 W. J. Gordy, J. Chem. Phys., 1947, 15, 305.

77 O. V. Shishkin, L. Gorb, P, Hobza, J. Leszczynski, Int. J. Quant. Chem., 2000, 80, 1116.

78 P. George, M. Trachtman, C. W.Bock, A. M. Brett, Theor. Chim. Act., 1975, 38, 121.

79 F. Biegler-König, J. Schönbohm, D. Bayles, AIM2000 - A Program to Analyze and Visualize Atoms in Molecules, J. Comp. Chem., 2001, 22, 545. 
80 AIMAll (Version 10.12.16), Todd A. Keith, 2010 (aim.tkgristmill.com)

81 R. Ponec, D. L. Cooper, J. Mol. Struct. (THEOCHEM), 2005, 727, 133.

82 W. Heyndrickx, E. Matito, P. Salvador, M. Sola, P. Bultinck, J. Comput. Chem., 2011, 32, 386.

83 A. M. K. Müller, Phys. Lett. A, 1984, 105, 446.

84 M. A. Buijse, E. J. Baerends, Mol. Phys., 2002, 100, 401.

85 E. Matito, M. Sola, P. Salvador, M. Duran, Farad. Discuss., 2007, 135, 325-345.

86 R. F. W. Bader, M. E. Stephens, J. Am. Chem. Soc., 1975, 97, 7391.

87 R. Carbó-Dorca, P. Bultinck, P., J. Math. Chem., 2004, 36, 201.

88 R. Carbó-Dorca, P. Bultinck, P., J. Math. Chem., 2004, 36, 231.

89 P. Bultinck, P., C. Van Alsenoy, P.W. Ayers, R. Carbó-Dorca, J. Chem. Phys., 2007, 126, 144111

90 P. Bultinck, P.W. Ayers, S. Fias, K. Tiels, C. Van Alsenoy, Chem. Phys. Lett., 2007, 444, 205.

91 F. Jensen, Introduction to computational chemistry, Wiley, Chichester (UK), 2007.

92 S. Van Damme, P. Bultinck, S. Fias, J. Chem. Theory and Comput., 2009, 5, 334-340.

93 A. T. Balaban, Z. Simon, Tetrahedron, 1962, 18, 315.

94 T. M. Krygowski, A. Ciesielski, C. W. Bird, A. Kotschy, J. Chem. Inf. Comput. Sci., 1995, 35, 203.

95 T. M. Krygowski, M. K. Cyranski, A. Ciesielski, B. Swirska, P. Leszczynski, J. Chem. Inf. Comput. Sci., 1996, 36, 1135.

96 P. Bultinck, Faraday Discussions, 2007, 135, 347.

97 K. B. Wiberg, Tetrahedron, 1968, 24, 1083.

98 M. Giambiagi, M. S. Giambiagi, D. R. Grempel, C. D. Heymann, J. Chim. Phys., 1975, 72, 15. 
99 I. Mayer, Chem. Phys. Lett., 1983, 97, 270.

100 J. P. Foster, F. Weinhold, J. Am. Chem. Soc., 1980, 102, 7211.

101 E. D. Glendening, F. Weinhold, J. Comp. Chem., 1998, 19, 593.

102 L. Pauling, J. Chem. Phys. , 1936, 4, 673.

103 F. London, J. Phys. Radium, 1933, 8, 397.

104 R. Ditchfield, Mol. Phys., 1974, 27, 789.

105 H. Fallah-Bagher-Shaidaei, C. S. Wannere, C. Corminboeuf, R. Puchta, P. v. R. Schleyer, Org. Lett., 2006, 8, 863.

106 A. Stanger, J. Org. Chem., 2006, 71, 883.

107 A. Soncini, P. W. Fowler, P. Lazzeretti, R. Zanasi, Chem. Phys. Lett., 2005, 401, 164.

108 S. Coriani, P. Lazzeretti, M. Malagoli, R. Zanasi, Theor. Chim. Acta, 1994, 89, 181.

109 P. Lazzeretti, M. Malagoli, R. Zanasi, Chem. Phys. Lett., 1994, 220, 299.

110 R. Zanasi, J. Chem. Phys., 1996, 105, 1460.

111 T. A. Keith, R. F. W. Bader, Chem. Phys. Lett., 1993, 210, 223.

112 E. Steiner, P. W. Fowler, J. Phys. Chem. A, 2001, 105, 9553.

113 E. Steiner, P. W. Fowler, Chem. Commun., 2001, p. 2220.

114 E. Steiner, P. W. Fowler, R. W. A. Havenith, J. Phys. Chem. A, 2002, 106, 7048.

115 Gaussian 03, Revision C.01, M. J. Frisch, G. W. Trucks, H. B. Schlegel, G. E. Scuseria, M. A. Robb, J. R. Cheeseman, J. A. Montgomery, Jr., T. Vreven, K. N. Kudin, J. C. Burant, J. M. Millam, S. S. Iyengar, J. Tomasi, V. Barone, B. Mennucci, M. Cossi, G. Scalmani, N. Rega, G. A. Petersson, H. Nakatsuji, M. Hada, M. Ehara, K. Toyota, R. Fukuda, J. Hasegawa, M. Ishida, T. Nakajima, Y. Honda, O. Kitao, H. Nakai, M. Klene, X. Li, J. E. Knox, H. P. Hratchian, J. B. Cross, V. Bakken, C. Adamo, J. Jaramillo, R. Gomperts, R. E. Stratmann, O. Yazyev, A. J. Austin, R. Cammi, C. Pomelli, J. W. Ochterski, P. Y. Ayala, K. Morokuma, G. A. Voth, P. Salvador, J. J. Dannenberg, V. G. Zakrzewski, S. Dapprich, A. D. Daniels, M. C. 
Strain, O. Farkas, D. K. Malick, A. D. Rabuck, K. Raghavachari, J. B. Foresman, J. V. Ortiz,

Q. Cui, A. G. Baboul, S. Clifford, J. Cioslowski, B. B. Stefanov, G. Liu, A. Liashenko, P.

Piskorz, I. Komaromi, R. L. Martin, D. J. Fox, T. Keith, M. A. Al-Laham, C. Y. Peng, A.

Nanayakkara, M. Challacombe, P. M. W. Gill, B. Johnson, W. Chen, M. W. Wong, C.

Gonzalez, J. A. Pople, Gaussian, Inc., Wallingford CT, 2004.

116 M. W. Schmidt, K. K. Baldridge, J. A. Boatz, S. T. Elbert, M. S. Gordon, J. H. Jensen, S.

Koseki, N. Matsunaga, K. A. Nguyen, S. J. Su, T. L.Windus, M. Dupuis, J. A. Montgomery, J. Comput. Chem., 1993, 14, 1347.

117 NBO 5.0. E. D. Glendening, J, K. Badenhoop, A. E. Reed, J. E. Carpenter, J. A.

Bohmann, C. M. Morales, F. Weinhold, Theoretical Chemistry Institute, University of

Wisconsin, Madison, 2001.

118 F. Feixas, E. Matito, J. Poater, M. Sola, J. Comput. Chem., 2008, 29, 1543.

119 C. Fonseca Guerra, J.-W. Handgraaf, E.J. Baerends, F.M. Bickelhaupt, J. Comput.

Chem., 2004, 25, 189.

120 P. Lazzeretti, Prog. Nucl. Magn. Res. Spectr., 2000, 36, 1.

121 J. A. N. F. Gomes, R. B. Mallion, Chem. Rev., 2001, 101, 1349.

122 T. Heine, C. Corminboeuf, G. Seifert, Chem. Rev., 2005, 105, 3889.

123 P. W. Fowler, M. Lillington, L. P. Olson, Pure Appl. Chem., 2007, 79, 969.

124 E. Steiner, P. W. Fowler, Int. J. Quantum Chem., 1998, 60, 609.

125 A. Soncini, C. Domene, J. J. Engelberts, P. W. Fowler, A. Rassat, J. H. van Lenthe. R. W.

A. Havenith, L. W. Jenneskens, Chem-Eur. J., 2005, 11, 1257.

126 R. Bast, J. Juselius, T. Saue, Chem. Phys., 2009, 356, 187.

127 D. B. Chesnut, Chem. Phys., 1998, 231, 1.

128 R. J. Abraham, M. Reid, J. Chem. Soc. Perkin Trans 2, 2002, 1081. 
129 F. A. Cotton, G. Wilkinson, Advanced Inorganic Chemistry (5th Edn), New York, Wiley, 1988, p. 1385.

130 F. De Proft, P. W. Fowler, R. W. A. Havenith, P. v. R. Schleyer, G. Van Lier, Paul.

Geerlings, Chem-Eur. J., 2004, 10, 940.

${ }^{131}$ Havenith, R.W.A.; De Proft, F.; Jenneskens, L.W.; Fowler, P.W., Chem-Eur. J.,2011, Submitted for publication. 